\title{
Ünal Kaya
}

Kastamonu University, ukayalkastamonu.edu.tr, Kastamonu-Turkey Murat Caner

Afyon Kocatepe University, mcanerdaku.edu.tr, Afyon-Turkey

Yüksel Oğuz

Afyon Kocatepe University, yukseloguzeaku.edu.tr, Afyon-Turkey

\author{
http://dx.doi.org/10.12739/NWSA.2016.11.3.2A0094
}

\section{RÜZGAR TÜRBİN MODELLERİ KULLANARAK KASTAMONU İLI RÜZGAR İLE ELEKTRIKK ÜRETIM POTANSIYYLI TAHMINI}

Öz

Bu çalışmada, çeşitli rüzgar türbin verileri ile iki farklı model oluşturularak Kastamonu ili rüzgar gücü potansiyeli tahmin edilmeye çalışılmıştır. Modelleme için seçilen türbinler Nordex 50, Vestas V66, Neg Micon 1000/60, Bonus 2MW, Vestas V90 ve Power Wind 90'dır. Bu türbinlere ait veriler türbin üretici kataloglarından alınan güç-rüzgâr hızı eğrilerinden elde edilmiştir. Güç tahmini için kullanılan 2015 yılına ait Kastamonu ili günlük maksimum rüzgâr hızı verileri, Meteoroloji Genel Müdürlüğünden alınmıştır. İki modelleme için sırasıyla Yapay sinir ă̆ları (YSA) ve çoklu adaptif bulanık sinir ağları (ANFIS) yöntemleri kullanılmıştır. Sonuç olarak kullanılacak türbin tipine göre üretilebilecek maksimum güç değerleri tahmin edilmiştir. Tahmin sonuçlarına göre Kastamonu'nun rüzgâr potansiyelinin oldukça iyi olduğu ve verimli türbinlerle yüksek kapasiteli enerji üretiminin sağlanabileceği görülmüştür.

Anahtar Kelimeler: Yapay Sinir Ağları, Rüzgâr, Rüzgâr Türbinleri, Rüzgâr Enerji Potansiyeli, Enerji

\section{WIND ENERGY POTENTIAL ESTIMATION VIA ARTIFICIAL NEURAL NETWORKS}

\section{ABSTRACT}

In this study, various turbines are modelled using two modelling method in order to estimate the wind power potential of the Kastamonu province. These turbines are Nordex 50, Vestas V66, Neg Micon 1000/60, Bonus 2MW, Vestas V90 and Power Wind 90. Their data were obtained from power production curves versus wind speed in manufacturer catalogues. The maximum daily wind speed data of the Kastamonu province in 2015 were obtained from the General Directorate of Meteorology for power estimation. Artificial Neural Networks (ANN) and Adaptive Neuro-Fuzzy Inference System (ANFIS) methods were used for modelling respectively. As a result maximum power values that can be produced have been estimated in terms of the turbine types. Results show that, wind potential of Kastamonu province is quite good and high energy capacity can be provided using productive turbines.

Keywords: Artificial Neural Networks, Adaptive Neuro-Fuzzy Inference System, Wind Turbines, Wind Power Potential 
Kaya, $\ddot{U}$. , Caner, M. ve Oğuz, Y. Technological Applied Sciences (NWSATAS), 2A0094, 2016; 11(3): 65-74.

\section{GÍRIŞ (INTRODUCTION)}

Elektrik enerjisine olan ihtiyaç sanayi ve teknolojinin gelişmesiyle daha da artmıştır. Artan enerji talepleri ülkemizde mevcut olan bazı enerji kaynaklarının kullanılması yönünde bir gereksinim oluşturmuştur. Yeryüzünde doğal enerji kaynakları hızla tükenmektedir. $\mathrm{Bu}$ durumdan dolayı toplumlar, doğal enerji kaynakları yerine daha ucuz ve çevreyi kirletmeyen özelliklerdeki yenilenebilir enerji kaynakları üzerinde çalışmalarını yoğunlaştırmışlardır [1]. Türkiye'nin coğrafi yapısı yenilenebilir enerji kaynaklarının kullanımı açısından avantajlı bir konumdadır. Hem çevre kirliliği hem de sürdürülebilir bir kalkınma için enerji tüketiminde yenilenebilir enerji kaynaklarının payının hızla arttırılması kaçınılmazdır [2]. Dünyanın dönüşü ve yüzeydeki düzensiz ısınma ve soğuma özelliğinden kaynaklanan rüzgar, tükenmesi için zaman biçilen fosil kaynakların aksine tükenmeyecek bir enerji kaynağıdır [3]. Türkiye' de ilk rüzgar enerji santrali ünvanına sahip 1.5 MW'lık Germiyan santrali 1998 yılında İzmir Alaçatı'da kurulmasına karşın rüzgar santralleri kurulu güç artışı 2004 yılı sonrasında başlamıştır [4].

Güncel verilerle Türkiye sahip olduğu 72.500 MW civarı kurulu güçle 260.000GWh civarı elektrik enerjisi üretmekte ve bir o kadar da tüketmektedir. 2014 yılı verileriyle rüzgar santrali kurulu gücü 3600MW, üretilen enerji ise 8366 GW civarına ulaşmıştır. Yani 2014 yılında toplam kurulu gücün 5'i ile toplam üretilen enerjinin $\% 3.3$ 'ü rüzgar enerjisinden üretilmiştir. Güncel olarak bu değerler \%6.5 ve \%4.8 civarında olup hızla artmakta ve tüketilen enerjinin $\% 10$ unun rüzgar enerjisinden karşılanması kısa vadeli hedef olarak görünmektedir [5 ve 6]. Kastamonu ile ise 54MW civarındaki kurulu gücünün büyük kısmı hidrolelektrik enerjiye dayalıdır. Rüzgar santrali 50MW güce sahip bir santral planlanmıştır. Aşağıda Enerji ve Tabii Kaynaklar Bakanıı̆̆ı Yenilenebilir Enerji Genel Müdürlüğünden alınan Kastamonu ili rüzgar hız dağılımı ve kullanılamaz alanlar ile 50 m’deki rüzgar hızı baz alınarak toplam kurulabilecek üretim gücü potansiyeli hakkında bilgiler verilmiştir [5 ve 6].

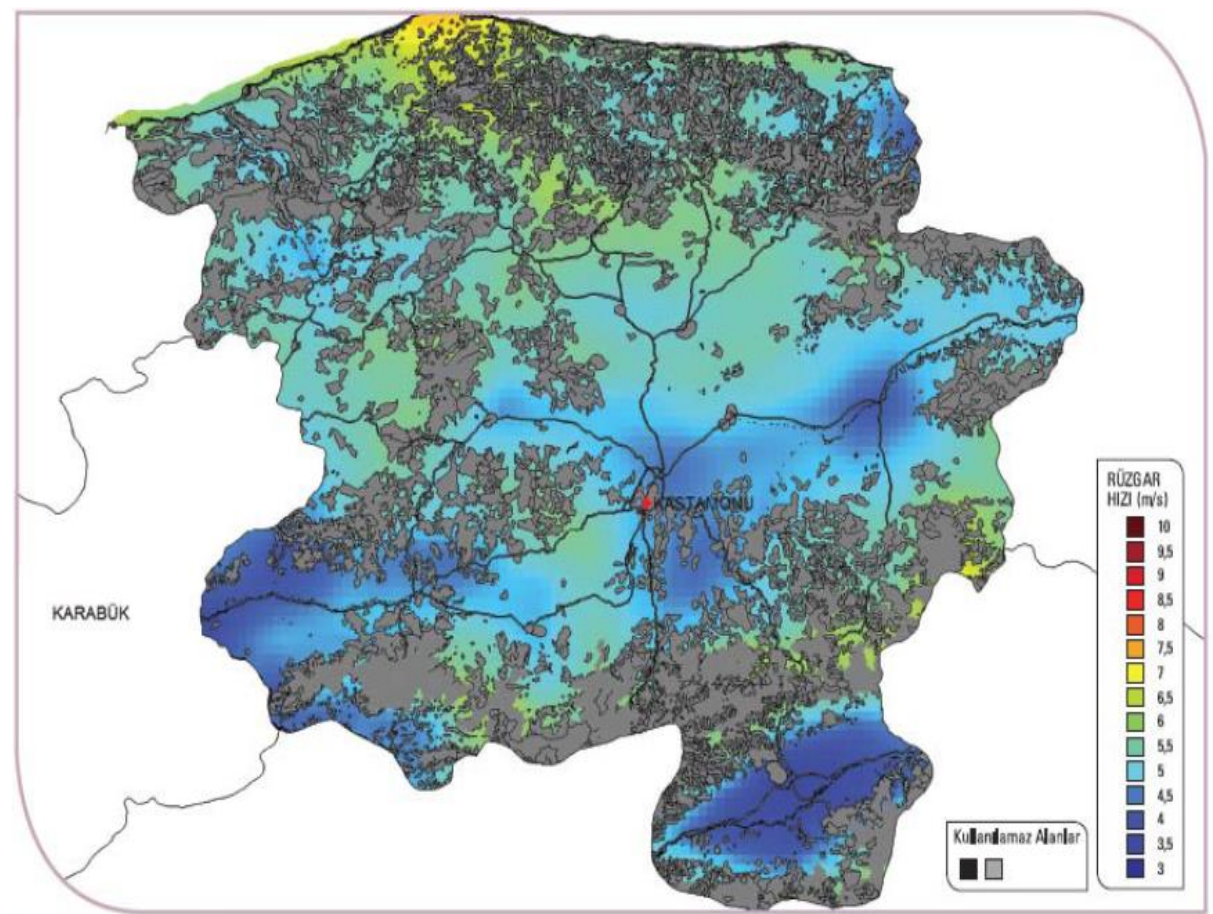

Sekil 1. Kastamonu ili rüzgar hız haritası ve kullanılamaz alanlar [7]

(Figure 1. Kastamonu province wind speed map and unavailable areas [7]) 
Kaya, ̈̈., Caner, M. ve Oğuz, Y. Technological Applied Sciences (NWSATAS), 2A0094, 2016; 11(3): 65-74.

Tablo 1. Kastamonu iline kurulabilecek rüzgar türbin gücü tahmini [7]

(Table 1. Power estimation of wind turbines that can be set up in Kastamonu Province [7])

\begin{tabular}{|c|c|c|c|}
\hline $\begin{array}{c}50 \mathrm{~m} \text { 'de Rüzgar } \\
\text { Gücü }\left(\mathrm{W} / \mathrm{m}^{2}\right)\end{array}$ & $\begin{array}{c}50 \mathrm{~m}{ }^{\prime} \text { de Rüzgar } \\
\text { Hızı (m/sn) }\end{array}$ & $\begin{array}{c}\text { Toplam Alan } \\
\left(\mathrm{km}^{2}\right)\end{array}$ & $\begin{array}{c}\text { Toplam Kurulu } \\
\text { Güç (MW) }\end{array}$ \\
\hline $300-400$ & $6.8-7.5$ & 79.9 & 399.52 \\
\hline $400-500$ & $7.5-8.1$ & 18.56 & 92.80 \\
\hline $500-600$ & $8.1-8.6$ & 4.51 & 22.56 \\
\hline $600-800$ & $8.6-9.5$ & 0.00 & 0.00 \\
\hline$>800$ & $>9.5$ & 0.00 & 0.00 \\
\hline & & 102.98 & 514.88 \\
\hline
\end{tabular}

Tokyo'da bir bölge için tüm yenilenebilir enerji çeşitleri kullanıldığında enerji potansiyeli hesaplanmış ve sanayi sektörü dışında şehrin ihtiyacından daha fazla enerji üretilebileceği belirtilmiştir [8]. Hindistan'ın bir bölgesinde 2013 yılına ait saatlik 10 m'de ölçülen rüzgar hızı verileri kullanılarak aylık değişim grafikleri elde edilmiş ve rüzgar gücü dağılımı hesaplanmıştır [3]

\section{2. ÇALIŞMANIN ÖNEMI (RESEARCH SIGNIFICANCE)}

Rüzgar santralleri kurulurken mevcut olan kaynağın daha verimli kullanılması için santrallerin kurulduğu yerler önemlidir. Rüzgar verimi yüksek olan yerleri tespit etmek rüzgar santrallerinin verimini yükseltecektir. Ancak verimli olduğu halde arazi şartları nedeniyle potansiyelin kullanımı her yerde mümkün değildir. Kastamonu ilinde bugüne değin rüzgar enerjisinden elektrik üretimi gerçekleştirilememiştir. Bu çalışmada Kastamonu il merkezinin rüzgar hız verileri kullanllarak belirlenen altı adet türbin tipi ile üretilecek toplam enerji tahmin çalışması yapılmıştır. Türbin tiplerinin rüzgar hızına göre enerji üretim değerleri YSA ve çoklu A-BSA ile modellenmiştir. Bu bağlamda Kastamonu ilinde yapılacak rüzgar enerji potansiyelinin önemine dikkat çekilerek rüzgar enerji yatırımlarına yön verilmesi amaçlanmıştır.

\section{MATERYAL VE METOT (MATERIAL AND METHOD)}

\subsection{Yapay Sinir Ağları (Artificial Neural Networks)}

Bilim adamları insan beyninin üstün özelliklerinden faydalanmak için beynin nörofiziksel yapısından esinlenerek matematiksel modeli çıkarmaya çalışılmışlardır. Beynin bütün davranışlarını tam olarak modelleyebilmek için fiziksel bileşenlerinin doğru olarak modellenmesi gerektiği düşüncesi ile çeşitli yapay hücre ve ağ modelleri geliştirilmiştir. Böylece Yapay Sinir Ağları denilen yeni bir bilim dalı ortaya çıkmıştır. Yapay sinir ağları günümüz bilgisayarlarının algoritmik hesaplama yönteminden farklı bir hesaplama algoritmasına sahiptir [9]. YSA, insan beynindeki nöron olarak isimlendirilen birçok sinir hücresinden oluşan biyolojik sinir ağlarının çalışma mekanizmasından esinlenerek geliştirilmiştir. Beynin temel özelliklerini modellemeye çalışarak verileri işleyecek şekilde tasarlanan bir sistemdir. Elektronik devrelerden oluşan yapılarla ya da bilgisayar yazılımları ile benzetimi yapılarak uygulanan YSA; beynin bilgi işleme yöntemine uygun bir öğrenme sürecinden sonra, bilgiyi toplama, bilgiyi saklama ve genelleme yeteneğine sahip bir işlemcidir [10]. Örneklerden elde ettikleri bilgiler ile kendi deneyimlerini oluşturur ve daha sonra benzer konularda benzer kararlar verirler [11]. Literatürde 100'den fazla YSA modeli vardır. Bazı bilim adamları, beynimizin güçlü düşünme, hatırlama ve problem çözme yeteneklerini bilgisayara aktarmaya çalışmışlardır. Bazı araştırmacılar ise, beynin fonksiyonlarını kısmen yerine getiren birçok modelleri oluşturmaya çalışmışlardır [12]. YSA' 
Kaya, ̈̈., Caner, M. ve Oğuz, Y. Technological Applied Sciences (NWSATAS), 2A0094, 2016; 11(3): 65-74.

lar özellikle eksik, belirsiz, karmaşık ve bulanık bilgileri işlemekteki başarıları nedeniyle, birçok endüstriyel probleme uygulanabilmektedir. Onların gerçek zamanlı olaylarda çalışmalarını sağlayan en büyük özellikleri ise çok hızlı çalışabilmeleridir [13]. Yapay nöronların birbirleriyle bağlantılar aracılığıyla bir araya gelmeleri YSA'yı oluşturmaktadır. YSA ile aslında biyolojik sinir ağının modeli oluşturulmak istenmektedir [14].

\subsection{Adaptif Bulanık-Sinir Ağları (Adaptif Neuro-Fuzzy Inference system)}

ANFIS yapısı, Sugeno tipi bulanık sistemlerin, sinirsel öğrenme kabiliyetine sahip bir ağ yapısı olarak temsilinden ibarettir. Bu ağ, her biri belli bir fonksiyonu gerçekleştirmek üzere, katmanlar halinde yerleştirilmiş düğümlerin birleşiminden oluşmuştur [15]. ANFIS yapısında, hem yapay sinir ağları hem de bulanık mantık kullanılır [16]. Yapı bakımından ANFIS, bulanık çıkarım sistemindeki eğer-ise kuralları ve giriş çıkış bilgi çiftlerinden oluşur [17]. Ancak sistem eğitiminde ve denetiminde YSA öğrenme algoritmaları kullanılır. Şekil 3'te birinci dereceden iki girişli bir ANFIS yapısı gösterilmiştir. ANFIS, 5 tabakalı ileri beslemeli bir yapay sinir ağı yapısına sahiptir. Bu tabakaların görevleri şu şekilde özetlenebilir [18].

- 1. Tabaka: Girdi değişkenlerinin her biri adaptif bir bağlantı ucu (node) oluşturur, yani, node sayısı girdi değişkeni sayısına eşittir. Bu değişkenlerin üyelik fonksiyonları node fonksiyonu olarak kullanılır. Bu üyelik fonksiyonlarının parametreleri "öncül parametreler" olarak adlandırılır.

- 2. Tabaka: Nodlar sabit karakterdedir. Node sayısı kural sayısına eşittir. Node girdileri, kuralların öncül kısmındaki değişkenlerin üyelik fonksiyon değerleri, node çıktıları ise, kuralların ağırlık dereceleri (firing strenght) dir

- 3. Tabaka: Node girdileri, kuralların ağırlık dereceleri, çıktıları ise, normalize edilmiş ağırlık dereceleridir. Yani bu tabakanın görevi, kuralların ağırlıklarını normalize etmektir.

- 4. Tabaka: Bu tabakadaki nodlar adaptifdir. Node fonksiyonu, Sugeno Sistemi'nde, herhangi bir mertebeden (çoğunlukla 1. mertebe) bir fonksiyondur. Model parametreleri, "berraklaştırma" veya "sonuç parametreleri" olarak adlandırılır.

- 5. Tabaka: Tek noddan ibaret olan bu tabakanın çıktısı, crisp karakterde model çıktısıdır.

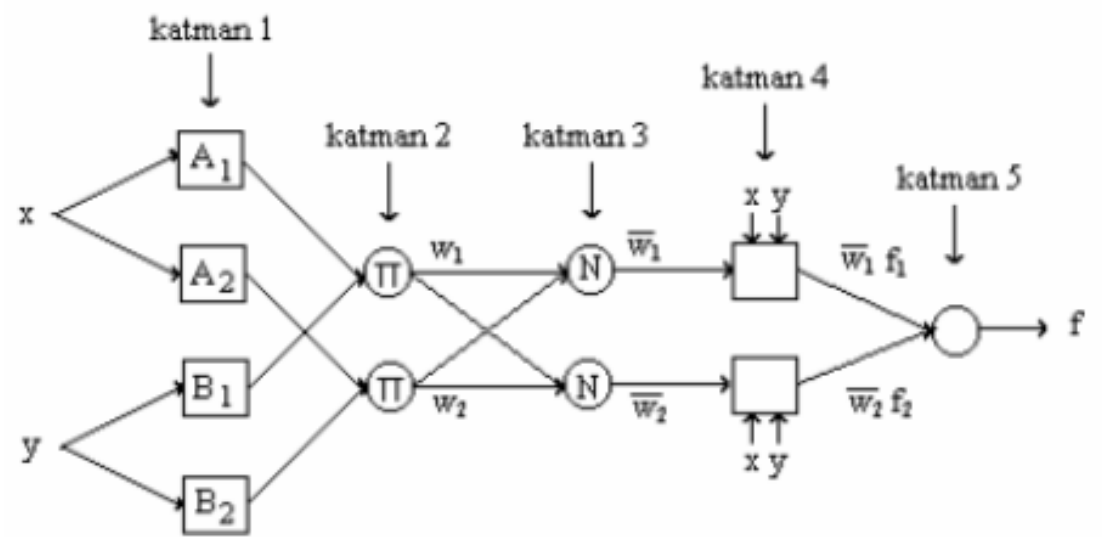

Şekil 2. Birinci dereceden iki girişli ve iki kurallı ANFIS yapısı (Figure 2. First order ANFIS structure with two inputs and two rules) 
Bu yapının parametreleri; öncül ve sonuç parametreleridir. Eğitim veri seti, bu yapay sinir ağına tanıtılır ve herhangi bir eğitme algoritması vasıtasıyla, eğitim veri setinde girdi-çıktı fonksiyonel ilişkisini en iyi şekilde öğrenir. Aslında bu işlem bir optimizasyon işleminden başka bir şey değildir. Model çıktısı ile eğitim veri seti çıktısı (ölçüm, deneysel sonuç vs.) arasındaki farkın kareler toplamı şeklinde ifade edilen hata fonksiyonunun minimum olduğu şartların bulunması, yani, parametrelerin optimum değerlerinin tespiti hedeflenir [19].

\subsection{Rüzgar Türbinlerinin Modellenmesi (Modelling of the Wind Turbines)}

Nordex 50, Vestas V66, Neg Micon 1000/60, Bonus 2MW, Vestas V90, Power Wind 90 tipi rüzgar türbinlerinde $0-26 \mathrm{~m} / \mathrm{s}$ arası rüzgar hızlarına verdikleri güç cevapları grafiksel olarak Şekil 4' de görülmektedir. Seçilen türbinlere ait grafiklerden eğitim aşamasında kullanılacak değerler elde edilmiş ve toplu bir şekilde Tablo 1 de gösterilmiştir.

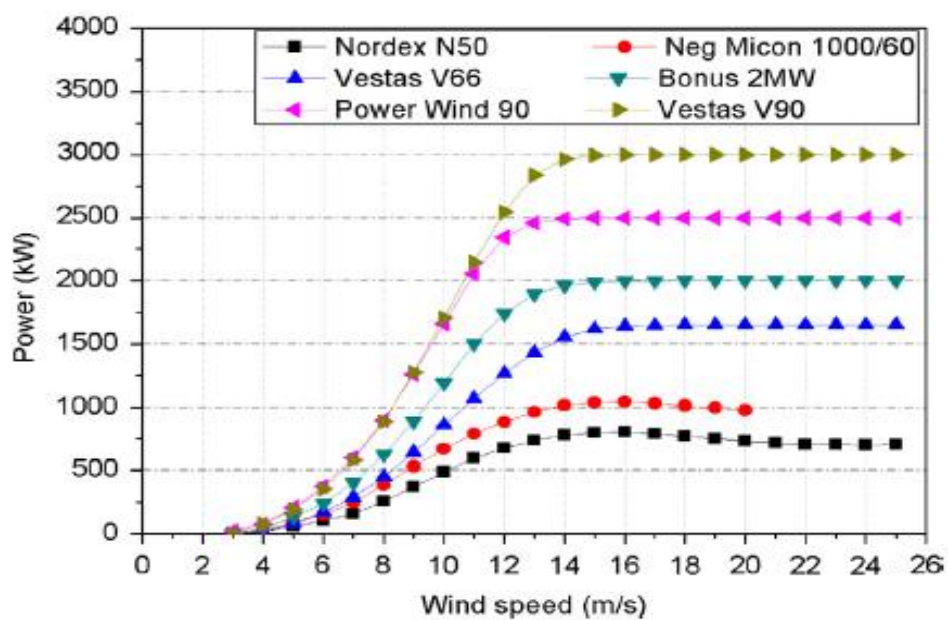

Şekil 3. Seçilen rüzgar türbinleri için güç eğrileri [20]

(Figure 3. The power curves for the selected wind turbines [20])

YSA modeli tasarımı ve eğitimi için Matlab nntool arayüzü kullanılmıştır. İleri beslemeli YSA yapısında rüzgar hızı giriş, 6 adet türbin tipi gücü ise çıkış olarak kullanılmıştır. Eğitim aşamasında öğrenme algoritması olarak "Levenberg Marquardt" yöntemi, performans fonksiyonu olarak ortalama karesel hata "mse" kullanılmıştır. Ağ yapısında sırasıyla 10 ve 9 hücreli 2 gizli katman kullanılmış ve tüm veriler randomize şekilde $\% 70$ eğitim, 15 doğrulama ve on test olarak ayrılmıştır. Eğitim aşaması ve durma kriterleri şekil 5'te özetlenmiştir.

\begin{tabular}{|c|c|c|c|}
\hline \multicolumn{4}{|l|}{ Progress } \\
\hline Epoch: & \multirow[t]{2}{*}{0} & 10 iterations & \multirow[t]{2}{*}{500} \\
\hline Time: & & $0: 00: 01$ & \\
\hline Performance: & 1.86 & 0.000802 & 0.00 \\
\hline Gradient: & 1.00 & 0.00147 & $1.00 \mathrm{e}-10$ \\
\hline Mu: & 0.00100 & 0.00100 & $1.00 \mathrm{e}+10$ \\
\hline Validation Checks: & 0 & 6 & 6 \\
\hline
\end{tabular}

Şekil4. YSA yöntemi eğitme parametreleri (Figure 4. Training parameters of the ANN) 
Kaya, $\ddot{U}$. , Caner, M. ve Oğuz, Y.

Technological Applied Sciences (NWSATAS), 2A0094, 2016; 11(3): 65-74.

Tablo 2. Modellemede kullanılan türbinlere ait veriler (Table 2. The turbine data used in modelling)

\begin{tabular}{|c|c|c|c|c|c|c|}
\hline Giriş & \multicolumn{6}{|c|}{ Çıkış Gücü (kW) } \\
\hline Rüzgar $\mathrm{H} ı \mathrm{zl}$ & Nordex & Neg Micon & Vestas & Bonus & Power Wind & Vestas \\
\hline$(\mathrm{M} / \mathrm{sn})$ & N50 (1) & $1000 / 60 \quad(2)$ & $\operatorname{V6} 6(3)$ & $2 \mathrm{MW}(4)$ & $90 \quad(5)$ & V90 (6) \\
\hline 1 & 0 & 0 & 0 & 0 & 0 & 0 \\
\hline 2 & 0 & 0 & 0 & 0 & 0 & 0 \\
\hline 3 & 0 & 0 & 0 & 0 & 0 & 0 \\
\hline 4 & 50 & 50 & 50 & 50 & 50 & 50 \\
\hline 5 & 70 & 80 & 90 & 100 & 100 & 110 \\
\hline 6 & 100 & 120 & 170 & 200 & 300 & 300 \\
\hline 7 & 200 & 220 & 250 & 400 & 570 & 570 \\
\hline 8 & 250 & 300 & 470 & 600 & 900 & 900 \\
\hline 9 & 370 & 510 & 570 & 800 & 1250 & 1270 \\
\hline 10 & 490 & 600 & 800 & 1190 & 1670 & 1700 \\
\hline 11 & 600 & 810 & 1100 & 1400 & 2100 & 2150 \\
\hline 12 & 700 & 900 & 1250 & 1750 & 2300 & 2520 \\
\hline 13 & 780 & 980 & 1470 & 1890 & 2500 & 2800 \\
\hline 14 & 800 & 1050 & 1520 & 2000 & 2500 & 3000 \\
\hline 15 & 780 & 1000 & 1680 & 2000 & 2500 & 3000 \\
\hline 16 & 750 & 1000 & 1680 & 2000 & 2500 & 3000 \\
\hline 17 & 760 & 1000 & 1680 & 2000 & 2500 & 3000 \\
\hline 18 & 750 & 1000 & 1680 & 2000 & 2500 & 3000 \\
\hline 19 & 750 & 1000 & 1680 & 2000 & 2500 & 3000 \\
\hline 20 & 750 & 1000 & 1680 & 2000 & 2500 & 3000 \\
\hline 21 & 750 & 1000 & 1680 & 2000 & 2500 & 3000 \\
\hline 22 & 750 & 1000 & 1680 & 2000 & 2500 & 3000 \\
\hline 23 & 750 & 1000 & 1680 & 2000 & 2500 & 3000 \\
\hline 24 & 750 & 1000 & 1680 & 2000 & 2500 & 3000 \\
\hline 25 & 750 & 1000 & 1680 & 2000 & 2500 & 3000 \\
\hline 26 & 750 & 1000 & 1680 & 2000 & 2500 & 3000 \\
\hline
\end{tabular}

ANFIS yapısı 6 adet çıkışa izin vermediği için 6 adet tek çıkışlı modelin birleşiminden oluşan çoklu ANFIS yapısı kullanılmıştır [21]. Tüm verideki eğitim, doğrulama ve test grupları, karşılaştırma açısından YSA da kullanılan indislerle elde edilmiştir. Üçgen üyelik fonskiyonu, 50 iterasyon, 0.04 minimum ortalama hata ve hibrid optimizasyon metodu kullanılan eğitim parametreleridir. Şekil 6 ve 7 'de YSA ve ANFIS modellerinde her bir türbine ait çıkış grafikleri gösterilmiştir. Tablo 2'de YSA ve ANFIS'te her bir türbin modeli için eğitme performansına ait regresyon değerleri verilmiştir. 


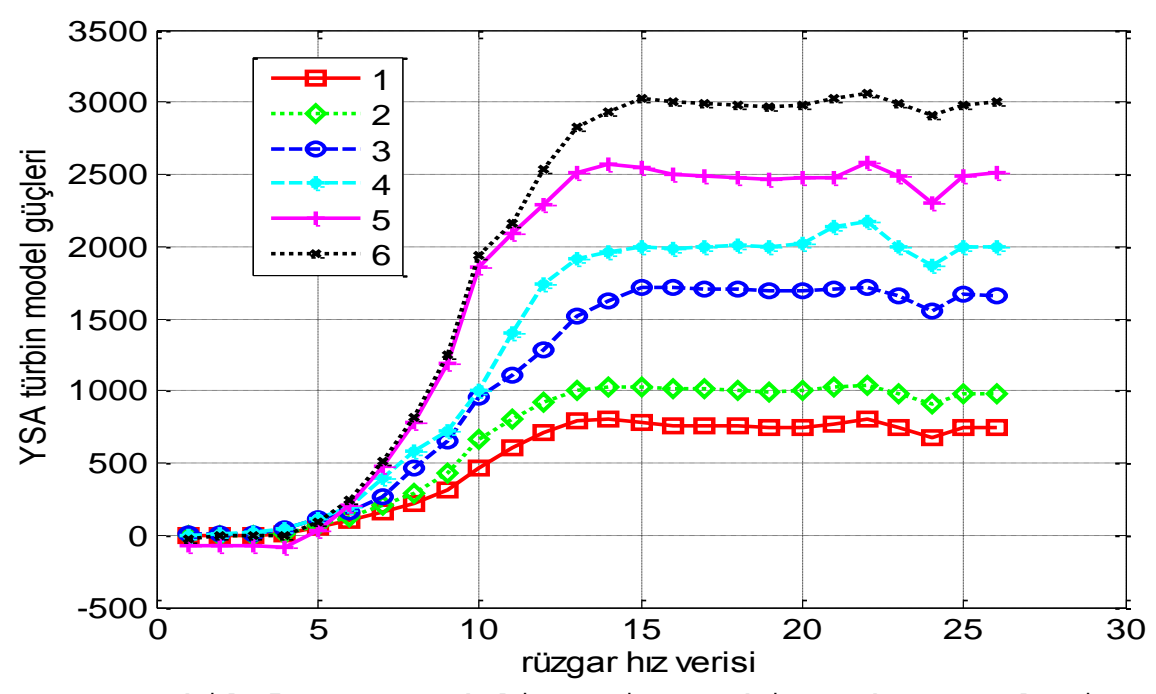

Şekil 5. YSA modeline ait türbin çıkış güçleri

(Figure 5. Outputs of the turbines modelled by ANN)

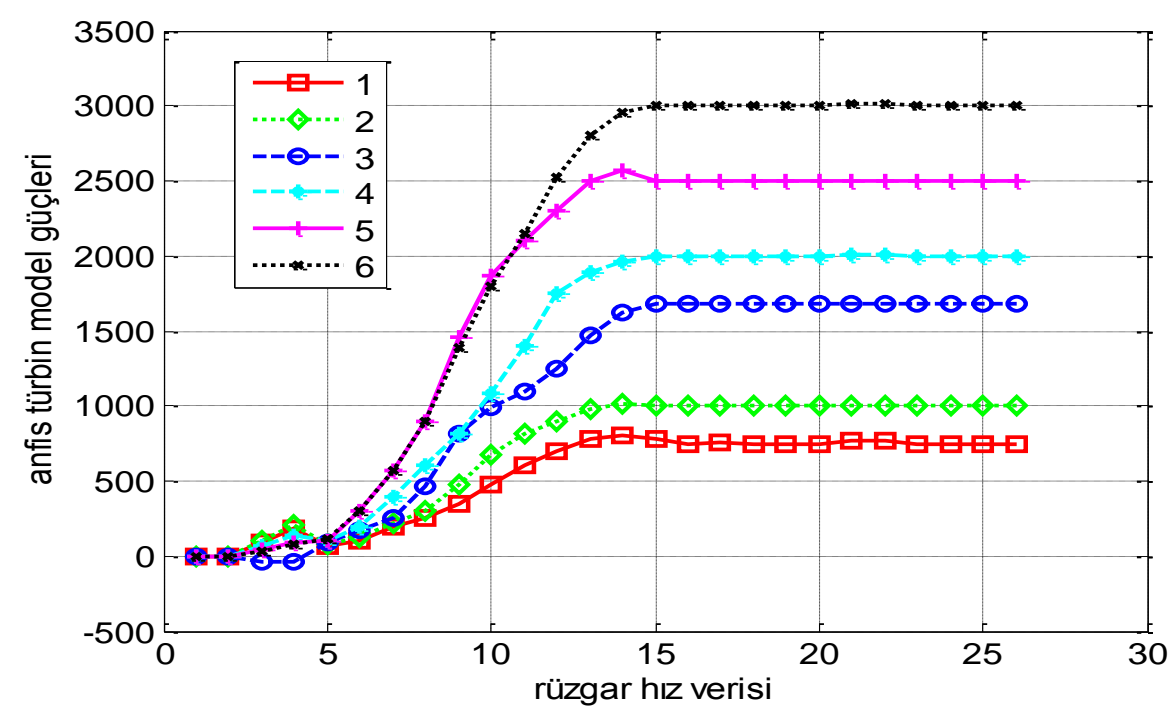

Şekil6.. ANFIS modeline ait türbin çıkış güçleri (Figure 6. Outputs of the turbines modelled by ANFIS)

Tablo 3. Çoklu ANFIS ve YSA için türbin modellerine ait regresyon değerleri Table 3. Regression values of the turbine models for multi-output ANFIS and ANN

\begin{tabular}{|c|c|c|r|c|c|}
\hline \multicolumn{2}{|c|}{ Çıkışlar } & Eğitim & Doğrulama & Test & Tüm \\
\hline \multirow{2}{*}{1} & ANFIS & 1,0000 & 0,9780 & 0,9999 & 0,9948 \\
\cline { 2 - 6 } & YSA & 0,9996 & 0,9976 & 0,9986 & 0,9975 \\
\hline \multirow{2}{*}{2} & ANFIS & 1,0000 & 0,9838 & 0,9995 & 0,9960 \\
\cline { 2 - 6 } & YSA & 0,9995 & 0,9829 & 0,9984 & 0,9971 \\
\hline \multirow{2}{*}{3} & ANFIS & 1,0000 & 0,9745 & 0,9985 & 0,9956 \\
\cline { 2 - 6 } & YSA & 0,9996 & 0,9856 & 0,9991 & 0,9976 \\
\hline \multirow{2}{*}{4} & ANFIS & 1,0000 & 0,9961 & 0,9997 & 0,9993 \\
\cline { 2 - 6 } & YSA & 0,9999 & 0,9976 & 0,9958 & 0,9969 \\
\hline \multirow{2}{*}{5} & ANFIS & 1,0000 & 0,9947 & 0,9997 & 0,9986 \\
\cline { 2 - 6 } & YSA & 0,9998 & 0,9865 & 0,9994 & 0,9981 \\
\hline \multirow{2}{*}{6} & ANFIS & 1,0000 & 0,9990 & 0,9999 & 0,9997 \\
\cline { 2 - 6 } & YSA & 0,9998 & 0,9927 & 0,9994 & 0,9989 \\
\hline
\end{tabular}


Kaya, $\ddot{U}$. , Caner, M. ve Oğuz, Y.

Technological Applied Sciences (NWSATAS), 2A0094, 2016; 11(3): 65-74.

\subsection{YSA ve ANFIS İle Kastamonu İlinin Rüzgar Gücü Potansiyelinin Tahmini (Estimation of Wind Power Potential of Kastamonu Province via ANN and ANFIS)}

Kastamonu ili aylık ortalama rüzgar hız verilerine karşılık olarak her bir türbine ait güç değerleri Tablo 2'de gösterilmiştir. Rüzgar verileri Meteoroloji müdürlüğünden alınan 2015 yılına ait günlük maksimum hız değerlerinin aylık ortalaması olarak hesaplanmıştır.

Tablo 4. YSA ve ANFIS modellerine göre tahmin edilen anlık güç değerleri

(Table 4. Instantaneous power values estimated by multi-output ANFIS and ANN)

\begin{tabular}{|c|c|c|c|c|c|c|c|c|}
\hline \multicolumn{2}{|c|}{ Giriş Verileri } & & \multicolumn{6}{|c|}{ Çıkış Verileri } \\
\hline Aylar & $\begin{array}{c}\text { Rüzgar } \\
\text { Hızı }\end{array}$ & & $\begin{array}{c}\text { Nordex } \\
\text { N50 } \\
\text { (1) }\end{array}$ & $\begin{array}{c}\text { Neg } \\
\text { Micon } \\
1000 / 60 \\
(2)\end{array}$ & $\begin{array}{c}\text { Vestas } \\
\text { V66 } \\
\text { (3) }\end{array}$ & $\begin{array}{c}\text { Bonus } \\
2 \mathrm{MW} \\
(4)\end{array}$ & $\begin{array}{c}\text { Power } \\
\text { Wind } 90 \\
\text { (5) }\end{array}$ & $\begin{array}{c}\text { Vestas } \\
\text { V90 } \\
(6)\end{array}$ \\
\hline \multirow{2}{*}{ Ocak } & \multirow{2}{*}{4,5} & YSA & 25,74 & 32,73 & 80,89 & 68,96 & 0,00 & 24,63 \\
\hline & & ANFIS & 110,81 & 121,91 & 29,91 & 101,26 & 73,24 & 73,27 \\
\hline \multirow{2}{*}{ Şubat } & \multirow{2}{*}{6,9} & YSA & 155,61 & 198,43 & 244,31 & 368,84 & 442,43 & 474,93 \\
\hline & & ANFIS & 197,38 & 216,98 & 234,69 & 380,60 & 549,35 & 545,45 \\
\hline \multirow{2}{*}{ Mart } & \multirow{2}{*}{6,2} & YSA & 109,11 & 141,06 & 170,57 & 222,94 & 248,92 & 276,74 \\
\hline & & ANFIS & 123,78 & 147,86 & 179,56 & 236,43 & 363,49 & 356,68 \\
\hline \multirow{2}{*}{ Nisan } & \multirow{2}{*}{8,8} & YSA & 289,56 & 388,02 & 602,81 & 681,73 & 1068,70 & 1121,80 \\
\hline & & ANFIS & 321,45 & 429,72 & 733,58 & 768,06 & 1326,33 & 1275,03 \\
\hline \multirow{2}{*}{ Mayıs } & \multirow{2}{*}{7,6} & YSA & 203,21 & 257,45 & 393,80 & 527,85 & 673,38 & 707,31 \\
\hline & & ANFIS & 224,75 & 257,06 & 367,40 & 518,66 & 740,96 & 749,51 \\
\hline \multirow{2}{*}{ Haziran } & \multirow{2}{*}{7,2} & YSA & 177,54 & 225,12 & 305,15 & 443,55 & 544,74 & 578,50 \\
\hline & & ANFIS & 206,48 & 228,68 & 284,27 & 439,10 & 617,95 & 623,65 \\
\hline \multirow{2}{*}{ Temmuz } & \multirow{2}{*}{7,4} & YSA & 191,06 & 241,89 & 350,46 & 489,03 & 611,64 & 645,56 \\
\hline & & ANFIS & 214,74 & 241,05 & 323,41 & 478,65 & 674,95 & 683,50 \\
\hline \multirow{2}{*}{ Ağustos } & \multirow{2}{*}{7,4} & YSA & 191,06 & 241,89 & 350,46 & 489,03 & 611,64 & 645,56 \\
\hline & & ANFIS & 214,74 & 241,05 & 323,41 & 478,65 & 674,95 & 683,50 \\
\hline \multirow{2}{*}{ Eylül } & \multirow{2}{*}{6,5} & YSA & 127,19 & 163,67 & 192,00 & 276,40 & 321,25 & 350,51 \\
\hline & & ANFIS & 170,44 & 202,00 & 189,89 & 301,30 & 473,33 & 453,33 \\
\hline \multirow{2}{*}{ Ekim } & \multirow{2}{*}{5,3} & YSA & 68,74 & 89,13 & 132,83 & 131,85 & 93,44 & 135,98 \\
\hline & & ANFIS & 63,42 & 74,65 & 119,63 & 115,64 & 139,48 & 150,68 \\
\hline \multirow{2}{*}{ Kasım } & \multirow{2}{*}{4,6} & YSA & 31,04 & 39,60 & 88,72 & 76,46 & 0,00 & 36,10 \\
\hline & & ANFIS & 99,65 & 110,22 & 43,00 & 98,27 & 74,68 & 77,50 \\
\hline \multirow{2}{*}{ Aralık } & \multirow{2}{*}{5,0} & YSA & 53,52 & 69,15 & 116,81 & 108,26 & 37,87 & 92,79 \\
\hline & & ANFIS & 69,99 & 79,99 & 90,00 & 99,99 & 99,99 & 109,99 \\
\hline
\end{tabular}

Buna göre en fazla güce sahip türbin tipi Power wind ve VESTAS V90'dır. Maksimum 1MW civarında güce çıkıldığı görülmektedir.

\section{SONUÇ VE ÖNERİLER (CONCLUSION AND RECOMMENDATIONS)}

$\mathrm{Bu}$ çalışmadaki temel amaç altı farklı rüzgar türbininin modellenmesi ve tahmin yöntemlerini kullanarak en küçük hata ile Kastamonu ilinin rüzgar gücü potansiyelini belirlemektir. Türbin modelleme çalışmalarında 26 adet verinin bir kısmı doğrulama bir kısmı da test grubu olarak ayrılmıştır. Modelleme eğrilerine bakıldığında ANFIS'e ait veriler daha güvenilir gözükmektedir. Ancak YSA'daki gibi altı çıkış tanımlanamadığından 1-giriş 1-çıkışlı 6 model oluşturmak gerektiğinden ANFIS'te bu problem için iş yükü fazla olmaktadır. Üretilecek güç Ekim-Şubat aralığında $500 \mathrm{~kW}^{\prime} ı$ n altında Mart-Eylül aralığında ise $500 \mathrm{~kW}$ üzerinde olmakla birlikte sadece Nisan ayında $1000 \mathrm{~kW}^{\prime} ı$ aşmaktadır. Buna göre maksimum 1MW'lık türbin kullanmak verim 
Kaya, ̈̈., Caner, M. ve Oğuz, Y. Technological Applied Sciences (NWSATAS), 2A0094, 2016; 11(3): 65-74.

açısından daha mantıklı olacaktır. Altı adet türbinin her birinin avantaj ve dezavantajları vardır. Bunlardan en önemlisi de maliyettir. Bu çalışmadan yola çıkarak rüzgar türbinlerinin maliyet analizleri ve fizibilite çalışmaları yapılabilir. Bu çalışmada rüzgar hızlarının geçerli olduğu yükseklik ve süre bilgisi eksik olduğundan bu bilgileri de içeren ayrıntılı verilerle daha sağlıklı olarak enerji potansiyeli hesaplaması yapılabilir.

\section{KAYNAKLAR (REFERENCES)}

1. Turgut, E. ve Selçuk, K., (2011). Elektrik Enerjisi Üretimi iletimi ve Dağılımı, Detay Yayıncılık, Ankara.

2. Önal, E. ve Yarbay, R.Z., (2010). Türkiye'de Yenilenebilir Enerji Kaynakları Potansiyeli ve Geleceği, İstanbul Ticaret Üniversitesi Fen Bilimleri Dergisi, Yıl:9, Sayı:18, Güz, ss:77-96.

3. Murthy, K.S.R. and Rahi, O.P., (2014). Statistical Estimation of Wind Power Potential at Hamirpur Region in Himachal Pradesh, India. 6th IEEE Power India International Conference 5-7th December 2014, pp:1-6.

4. http://demirer.com.tr/santral/alize/cesme/index.html. (Erişim: Nisan 2016)

5. Türkiye Elektrik Üretimi A.Ş. Web sitesi. http://www.teias.gov.tr/TC 3BCrkiyeElektrikC 4B 0statistikleri/is tatistik2014/istatistik2014.htm (Erişim: Nisan 2016)

6. Enerji Atlası. http://www.enerjiatlasi.com/sehir/kastamonu/ (Erişim: Nisan 2016)

7. Kastamonu-REPA Web Sitesi. http://www.eie.gov.tr/YEKrepa/KASTAMONU-REPA.pdf

8. (Erişim: Nisan 2016)

9. Wakeyama, T. and Ehara, S., (2010). Potential Estimation of Renewable Energy Resource in Tohoku Area and Tokyo metropolitan, Japan., 2010 International Conference on Environmental Engineering and Applications (ICEEA 2010)

10. Yurtoğlu, H., (2006). Yapay Sinir Ağlan Metodolojisi ile Öngörü Modellemesi, Yıldız Teknik Üniversitesi Sosyal Bilimler Enstitüsü Uzmanlık Tezi.

11. Sağıroğlu, Ş., (2001). Yapay Sinir Ağları ve Mühendislik Uygulamalari Semineri, Erciyes Üniversitesi Mühendislik Fakültesi Bilgisayar Mühendisliği. Erciyes.

12. Öztemel, E., (2003). Yapay Sinir Ağları, Papatya Yayıncılık, İstanbul.

13. Elmas, Ç., (2003). Yapay Sinir Ağları, Seçkin Yayınevi, Ankara.

14. Bayır, R., (2008). Yapay Zeka Teknikleri Dersi Ders Notları. Karabük Üniversitesi Elektronik ve Bilgisayar Eğitimi bölümü.

15. Saraç, T., (2004). Yapay Sinir Ağlan Seminer Projesi, Gazi Üniversitesi Endüstri Mühendisliği Bölümü, Ankara.

16. Tsoukalas, L.H. and Uhrig, R.E., (1996). Fuzzy and Neural Approaches in Engineering. John Wiley \& Sons, Inc, New York.

17. Kosko, B., (1991). Neural Networks and Fuzzy Systems, A Dynamical Systems Approach, Englewood Ciffs., NJ: Prentice Hall.

18. Jang, J.S.R., (1993). ANFIS: Adaptive Network-Based Fuzzy Inference Systems, IEEE Trans. Syst., Man. and Cybern. Vol:23, $\mathrm{pp}: 665-685$.

19. Jang, J.S.R, Sun, C.T., and Mizutani, E., (1997). Neuro-fuzzy and Soft Computing: a Computational Approach to Learning and Machine Intelligence, Prentice Hall, N.J.

20. Perez, P., (2001). Prediction of Sulfur Dioxide Concentration at a Site Near Downtown Santiago, Chile, Atmospheric Environment. (35), 4929-4935. 
Kaya, Ü., Caner, M. ve Oğuz, Y. Technological Applied Sciences (NWSATAS), 2A0094, 2016; 11(3): 65-74.

21. Boudia, S.M. and Guerri, Q., (2015). Investigation of Wind Power Potential at Oran, Northwest of Algeria, Energy Conversion and Management, 105, 81-92.

22. Benmiloud. T., (?). Multioutput Adaptive Neuro-Fuzzy Inference System, Recent Advances in Neural Networks, Fuzzy Systems \& Evolutionary Computing, ISBN: 978-960-474-195-3. 